\section{Analysis of Primary School Teachers' Knowledge of Geometry}

\author{
Gamze Kurt-Birel ${ }^{\mathrm{a},{ }^{*},}$ Şule Deniz ${ }^{\mathrm{b}}$, Fatih Önelc
}

\begin{tabular}{ll}
\hline Received: & 11 December 2019 \\
Revised: $\quad$ & 14 January 2020 \\
Accepted: & 10 February 2020 \\
ISSN: $1307-9298$ \\
Copyright @ IEJEE \\
www.iejee.com
\end{tabular}

DOI: $10.26822 /$ iejee.2020459459

\begin{abstract}
This study investigated the geometry knowledge of in-service primary school teachers through measuring both their content knowledge (CK) and pedagogical content knowledge (PCK) using a descriptive and qualitative approach. The participants of the study were 23 primary school teachers who work in public schools with teaching experience that ranges from six months to 30 years. The teachers voluntarily attended a teacher-training seminar conducted by the researchers and completed a test, which included open-ended questions. This particular study presented here is part of a larger design-based research project on a seminar that trains primary teachers to teach mathematics. The collected data were analysed through qualitative data analysis techniques with a holistic approach and discussion. The findings are presented according to the three geometric concepts that the study focused on: quadrilaterals, angle measurement and transformation geometry. On the whole, the study found that the CK of the primary school teachers was weak. We also found that the teachers' PCK was weaker than their CK due to the relationship between CK and PCK. Hence, primary school teachers should be offered additional teacher training sessions for the purpose of improving both CK and PCK, which will, in turn, enhance the learning opportunities of their students.
\end{abstract}

Keywords: Geometry Knowledge, Content Knowledge (CK), In-Service Primary School Teachers, Mathematics Teaching, Pedagogical Content Knowledge (PCK).

\section{Introduction}

Students are typically exposed to fundamental mathematical concepts for the first time during their primary level of education. The learning opportunities of students are directly related to the knowledge of their teachers, including primary school teachers. For this reason, it is worth analysing the knowledge that primary school teachers are required to have to effectively teach mathematics. Content knowledge (CK) and pedagogical content knowledge (PCK) are the two knowledge dimensions which are highly related with each other and have an impact on students' learning and motivation (Kleickmann et al., 2013; Krauss et al., 2008).

Recent research indicates that primary school teachers, as well as pre-service teachers, have weak knowledge of CK and PCK (Venkat \& Spaull, 2015; Turnuklu \& Yesildere, 2007) regarding the teaching of geometry (Jones et al., 2002; Hourigan \& Leavy, 2017; Fujita \& Jones, 2006; Jones \& Tzekaki, 2016) in different contexts such as quadrilaterals, geometric thinking, or spatial reasoning/ability. Although there are studies on the knowledge needed to teach geometry, many of them include pre-service primary teachers or they define the primary level of education as the first eight years of learning and include a broad range of K-8 (Browning et al., 2014). The shortcomings of these studies have led us to focus more specifically on the CK and PCK of in-service primary school teachers in teaching geometry. Therefore, the CK highlighted in this study refers to geometry content knowledge or the knowledge that teachers will use in the teaching of geometry. Jones (2002) describes teaching geometry as knowing how to recognize interesting geometric problems and theorems, valuing the historical and cultural context in which they are taught, and understanding the many different ways in which geometry can be integrated (p. 122). PCK refers to knowing how to transfer this professional knowledge to students. Geometry CK should be evaluated within the CK that teachers should have in order to teach mathematics more broadly. Studies show that the CK of teachers and/or prospective teachers is lower in geometry content than in other subjects (Marchis, 2012; Tsang \& Rowland, 2005). Moreover, there are studies which examine the relationship between teachers' knowledge of geometry and the way in which students learn (Unal et al., 2009). That is, the geometric thinking skills that students are expected to acquire are a function of how the teachers themselves develop their own knowledge of geometry. What teachers teach and how they transfer that knowledge to their students directly affects student learning comprehension. The intention of our study is to describe the CK and PCK needs of in-service primary teachers in order to teach geometry, contributing to a gap in the literature on in-service primary teachers. The primary teachers of this study are those responsible for the first four years of primary education in Turkey.

The skills expected from students such as critical thinking, intuitive decision-making, problem solving and logical reasoning, which are all key components of the current national mathematics curriculum, can be developed through geometry teaching. It is thus critical to examine the geometry knowledge of teachers (Ministry of National Education [MoNE], 2018). Being closely associated with mathematical concepts, possessing intuitive, visual and aesthetic features, and bringing creativity to the forefront are all inherent in the geometry. For this reason, teaching geometry requires a special effort At the same time, it is important to investigate teachers' ability to teach geometry (Jones, 2002). With the development of information technologies and the emergence of new uses of geometry, ranging from animation to global positioning systems, teaching geometry is particularly rele- 
vant today. The aim of this study is to describe and investigate the geometry knowledge of in-service primary school teachers in terms of their CK and PCK. For this purpose, the following research questions were asked:

1. How could the knowledge of in-service primary school teachers need to teach geometry be described, in terms of both CK and PCK?

2. How could the CK and PCK needed by in-service primary school teachers to teach geometry be intertwined?

\section{Literature Review}

For decades, researchers have been interested in understanding what teachers need to know for the teaching of mathematics, and this knowledge package required to teach mathematics continues to evolve. Shulman's (1987) idea of the fundamental level of knowledge needed for teaching began to develop with the definition of PCK. This conceptual expansion could be seen in one of the widely accepted knowledge packages presented as knowledge needed to teach mathematics by Hill et al. (2008). In response to Shulman's introduction of PCK, various knowledge packages were proposed, with one of the most popular presenting the knowledge needed for teaching mathematics as a combination of knowledge types in different dimensions (Ball et al., 2008). The knowledge package presented by Hill et al. (2008) is depicted in Figure 1 below:

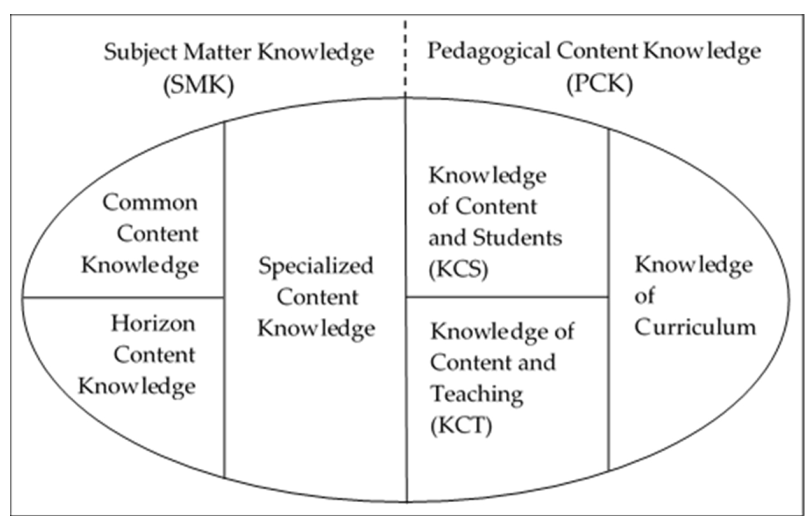

Figure 1. The Required Knowledge Package for Teaching Mathematics (Hill et al., 2008)

Researchers argued that teachers should have advanced PCK. Superior knowledge of content alone is necessary but insufficient to teach mathematics. What is also needed is an understanding of how to apply knowledge of the subject matter when teaching mathematics (Ball et al., 2008; Hill et al., 2008). CK or subject matter knowledge can be defined as the professional knowledge required in a specific subject (Ball et al., 2008). As seen above, CK is composed of three categories: common content knowledge (CCK), which is general mathematical understanding in a non-teaching context; specialized content knowledge (SCK) which is the knowledge specifically needed to teach mathematics; and horizon knowledge, which refers to the ability to understand the relationships between different mathematical concepts throughout the mathematics curriculum (Ball et al., 2008). SCK is prominent in the practice of teaching as a profession; knowing a subject not only requires having knowledge of the truths or concepts about a particular subject, but also refers to being able to identify and explain the relationships between concepts (Hill et al., 2004; Ball et al., 2005). The researchers further characterized PCK in terms of knowledge of content and students (KCS) and knowledge of content and teaching (KCT) (Ball et al., 2008). While the KCS dimension is defined as the ability to modify teaching by taking into account both students and mathematics, the KCT dimension refers to the ability to adjust teaching according to both the method of instruction and mathematics.
The knowledge required to teach mathematics has also been researched in different contexts related to problem solving, to validating the knowledge dimensions and to revealing the relationships between the knowledge dimensions (Chapman, 2015; Knievel et al., 2015; Hoover et al., 2016; Charalambous, 2016). In teacher knowledge frameworks utilizing PCK, as well as in the Technological Pedagogical Content Knowledge (TPACK) framework, various studies have investigated the relationship between the CK and PCK knowledge dimensions (Kleickmann et al., 2013; Krauss et al., 2008).

In the case of research on primary school teachers, there are studies which have reported a low level of mathematics subject matter knowledge, although only a few specifically investigated CK for teaching geometry (Hourigan \& Leavy, 2017; Jones \& Tzekaki, 2016). Jones et al. (2002) state that pre-service teachers assume geometry to be the least prioritized subject within the mathematics curriculum. An analysis of the geometry domain in the Turkish primary school mathematics curriculum reveals four different sub-domains: geometric shapes and solids; spatial relationships (congruent things, symmetry, symmetry line and reflection symmetry); geometric patterns (patterns including shapes, and tessellations with two-three different shapes); and fundamental concepts in geometry (point, line, line segment, half-line, plane, angle, acute angle, obtuse angle, right angle, and straight angle) (MoNE, 2018). Primary school teachers are responsible for teaching these geometry concepts to students from grade one to four.

A review of the related literature finds that many of the studies focus on the geometric thinking skills and levels of teachers and prospective teachers, with a majority of the studies conducted with prospective teachers. Some of these studies are quantitative, examining the participants' geometric thinking skills with other variables such as gender or spatial ability (Turgut \& Yılmaz, 2012). Other research focuses on related concepts within the framework of geometric thinking, for example, geometric transformations or transformational geometry (Yanık, 2011), or examines them in a more specific context, including geometric discourse (Wang \& Kinzel, 2014) and geometric habits of mind (Köse \& Tanışlı, 2014). Wang and Kinzel (2014) examined the parallelogram knowledge of prospective primary and elementary school mathematics teachers. The participants were asked to classify a group of geometric shapes (quadrilaterals), and then researchers evaluated their understanding of the characteristics of the parallelogram. The findings of the study indicate that, although the prospective teachers were at the same van Hiele geometric level, participants show that they could have a different geometric discourse but they were weak in justification and definition (Wang \& Kinzel, 2014). In another study conducted specifically on geometric shapes and their characteristics, van Hiele geometric thinking levels of prospective primary school teachers were evaluated through a knowledge test (Žilková, Gunčaga \& Kopáčová, 2015). Focusing on the ability to recognize two-dimensional shapes and questioning the basic features of the shapes, the researchers found that the participants' geometric thinking levels were quite low and that they were less successful in answering questions about the parallelogram than the other quadrilaterals.

A study conducted by Aslan-Tutak and Adams (2015) aimed to improve the CK of geometry of 102 prospective primary school teachers. As a result of activities incorporated into the pre-service teachers' mathematics teaching methods course, there was a significant difference in the development of pre-service teachers' geometry CK. Furthermore, the participants in the study were aware of the deficiencies in their geometry CK and the researchers claimed that they were not yet ready to teach geometry. In another study conducted by Toluk-Uçar (2011) that sought to determine the PCK of prospective primary school teachers and mathematics teachers, the teachers were asked to make instructional explanations on various subjects including geometry. The research concluded that the teacher 
candidates' answers to the questions were largely based on memorization and that they were unable to make instructional explanations of the subject.

\section{Methodology}

This study is a small part of a design-based research project which explores the design process of an in-service teacher training seminar that develops primary school teachers' CK and PCK needed to teach mathematics. The seminar was announced to all teachers throughout the province with the cooperation of the provincial directorate of national education and a teacher institution founded in the university for teachers. A total of 23 teachers, made up of eight men and 15 women, volunteered to attend the seminar. A majority of the teachers, 17 , have 10 to 20 years of teaching experience. While a newly appointed teacher with the least experience had been teaching for only six months, the participant with the greatest experience had been teaching for 30 years. Seven of the participants had graduated from faculties other than the department of primary school teaching, including biology teaching, physics, and geophysical engineering, among others.

At the beginning of the seminar, the teachers were examined in a test which took approximately 40-50 minutes, consisting of 19 questions assessing mathematics CK and 15 questions assessing PCK. This test is a Turkish version of a multifaceted test used by Callingham et al. (2011) in their studies. This test was chosen because its questions are organized in three separate sections of CK, PCK and beliefs, while including all learning areas in the primary school mathematics curriculum. The CK and PCK sections consist of open-ended and interpretive questions. In our study, the test was translated into the Turkish language in order to evaluate the knowledge needed by primary school teachers to teach mathematics, and was applied to the participants in two separate sections.

The study summarized here encompasses an analysis of geometry-related items in the test. In order to assess the knowledge of geometry of primary school teachers, the responses were examined through qualitative data analysis. Three questions were selected from the CK section and three from the PCK section. Figure 2 below provides an illustration of the exam questions, depicting the shell question as it relates to angle measurement in the CK section.

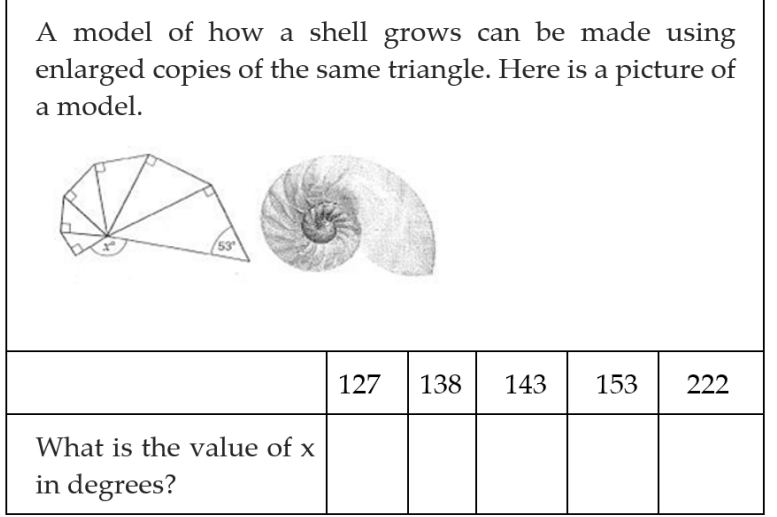

Figure 2. A Sample CK Question: The Shell Question and Angle Measurement

Another question in the CK section asks whether a given definition/explanation of basic concepts of transformation geometry, such as translation, congruency, and similarity, is right or wrong. In this question, each alternative was evaluated separately. The last question in the CK section asks whether the given seven quadrilaterals/polygons are paral- lelograms or not. The answers to this question were evaluated in the same manner as those to the previous question.

In the PCK section, teachers were requested to provide the best possible feedback to a student according to a particular situation. A sample question of this section is provided in Figure 3 below. This question examines the relationship between a square and a rectangle and is analyzed below in the quadrilaterals section on findings. Another question in the PCK section assesses the responses of the teacher to a student's measurement using the protractor and is analyzed below in the angle measurement section on findings. The last PCK question examines how the teacher would explain the relationship between the rhombus and other quadrilaterals.

Ann and Bob are Year Six students completing a task in which they are asked to investigate the areas of rectangles with a perimeter of $24 \mathrm{~cm}$. Ann claims that the maximum area is $36 \mathrm{~cm}^{2}$, while Bob claims that it is $35 \mathrm{~cm}^{2}$. Which of the following is the most likely explanation of why one of them is incorrect?

$\square \quad$ Ann is incorrect because she has not understood the

difference between a

square and a rectangle.

$\square \quad$ Ann is incorrect because she has calculated 5.9 by 6.1 and rounded up.

$\square \quad$ Bob is incorrect because he thinks squares are not rectangles. $\square \quad$ Bob is incorrect because he has only used whole numbers instead of decimals.

Figure 3. A Sample PCK Question: The Relationship Between a Square and Rectangle.

The teachers were asked to use the empty spaces in the test paper to show their work while answering the test. Explanations were provided to the participants to the questions they posed regarding aspects of the exam that they did not understand.

The study described here adopts a descriptive approach in terms of its purpose and a qualitative research approach in terms of the inquiry method (Kumar, 2019; Creswell, 2007). Descriptive research collects information for the purpose of systematically defining and describing a situation, a problem, a phenomenon, a seminar or a program. In this study, examining the geometry knowledge of in-service teachers in terms of CK and PCK constitutes a descriptive approach. In the same manner, the systematic analysis of the collected data through qualitative data analysis constitutes a qualitative approach.

Qualitative data analysis was carried out according to a previously prepared rubric by the researchers. For example, in the case of the shell question, there is only one correct response and the participants were evaluated on that basis. The participants' working out of the problems on the test paper and their incorrect responses were analyzed as well. The quadrilateral question has seven options from which to select the correct answer and each alternative was evaluated separately. For the rhombus question, teachers were requested to choose whether the listed feedback should be given, may be given or should not be given. Consequently, the responses of the participants were evaluated as a correct response, partially correct, or wrong. In the overall assessment of each participant, the answer to each question was analyzed separately.

\section{Findings}

The presentation of the findings is organized in three sections that correspond to the data analysis: quadrilaterals, angle measurement and transformation geometry. 


\section{Quadrilaterals}

First, only six of the participants correctly interpreted the relationship between the parallelogram and the other seven shapes of the listed quadrilaterals, one of which was a hexagon. Twelve of the participants claimed that the hexagon and the trapezoid were a parallelogram. The rest of the participants were undecided about whether the square and rectangle were a parallelogram and left the answer blank. Figure 4 below shows the response of one of the participants to this question.

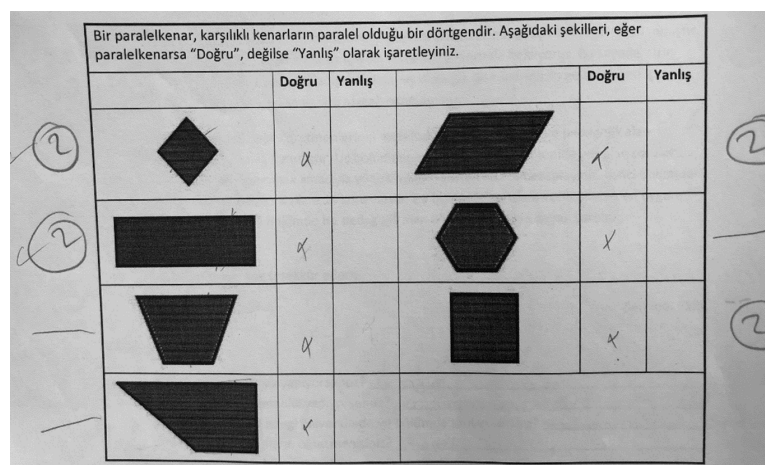

Figure 4. A Test Response to the Quadrilateral Question.

22 of 23 respondents answered at least one option incorrectly or left the answer blank in the rhombus question in the PCK section. Some of the study participants made comments on the exam and selected the options but did not answer correctly. Our interpretation is that the participants are familiar with geometric shapes at a basic level, but lack an understanding of the relationships among the quadrilaterals. Figure 5 below shows one of the responses to this question.

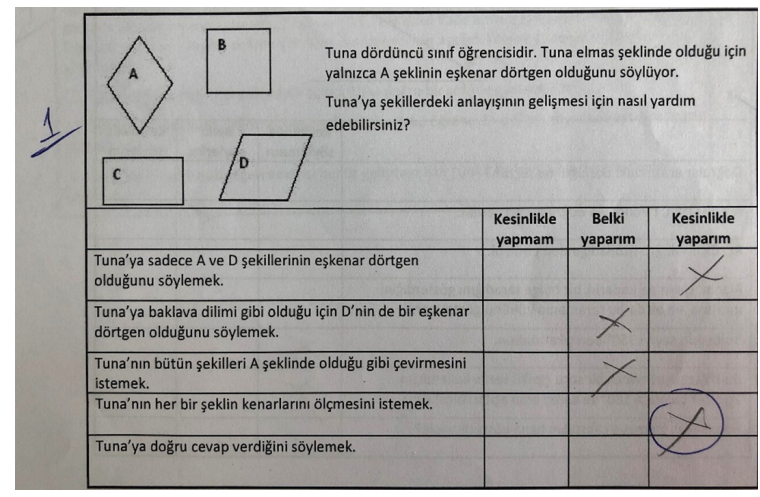

Figure 5. A Test Response to the Rhombus Question.

The other question in the PCK section which examined the relationship between a square and a rectangle is a multiple-choice question and has only one correct answer. 19 of the 23 participants answered this question incorrectly, choosing to give inappropriate feedback to their students. This indicates that they did not understand the relationship between a square and a rectangle.

It is evident that the participants lack general knowledge of the relationships among quadrilaterals. They do not understand what a parallelogram/rhombus is, or how it can be described. That they do not consider that the square is a rectangle also suggests that they lack CK regarding the classification of quadrilaterals. Indeed, the participants' lack of PCK regarding quadrilaterals is directly correlated with their inadequate CK.

\section{Angle Measurement}

The angle measurement category contained both a CK and a PCK question. In the shell question assessing CK, a shell model is created by sequentially resizing the same triangle and com- bining the resulting triangles and asking the measurement of an unknown angle in the model. The teacher is expected to calculate the measure of that angle while showing her progress on the test sheet. Only five of the 23 participants gave the correct answer and nine of the teachers responded incorrectly. All nine teachers who gave the incorrect response did so because of their assumptions regarding the linearity of nonlinear parts. They thought that the unknown angle and the angle that measured $37^{\circ}$ degrees were supplementary angles. Figure 6 below shows one of the incorrect responses given in this way.

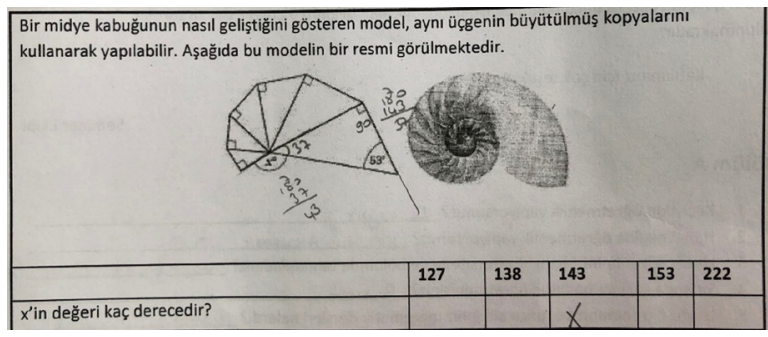

Figure 6. A Test Response to the Shell Question.

For the remaining responses to the shell question, three teachers answered incorrectly because they did not understand the similarity of the polygons. Nevertheless, these three participants all knew that the sum of the interior angles was $180^{\circ}$ degrees. All other responses were incorrect either due to the calculations or to the way in which the problem was solved, such as using the exterior angles.

The PCK question in the angle measurement category investigated the possible feedback that a primary school teacher might give to a student while measuring an angle using the protractor. The hypothetical student in the PCK question measured the shown angle as $30^{\circ}$. The question required the participants to determine which of the possible seven feedbacks or reactions they would definitely make, which they might make, and which they would not make. The number of correct responses regarding the appropriate feedback is detailed in Table 1 below.

Table 1. Participant Responses to the Question of Angle Measurement responses

\begin{tabular}{lr}
\hline Did you measure the amount of space between the lines? & 3 \\
\hline Well done, Kylie, you're absolutely correct. & 7 \\
\hline Make sure you line up the protractor correctly. & 1 \\
\hline $\begin{array}{l}\text { Remember that angles are about the amount of turn, and } \\
\text { the arrow shows the direction of turn. }\end{array}$ & 8 \\
\hline You need to subtract that from $360^{\circ}$. & 4 \\
\hline $\begin{array}{l}\text { This one's tricky because your protractor will only meas- } \\
\text { ure angles up to } 180^{\circ}\end{array}$ & 4 \\
\hline Can you show me which angle you are trying to measure? & 11 \\
\hline
\end{tabular}

It is evident that most of the participants did not react appropriately or provide the right feedback to student error, their principal mistake being to guide the pupil to the correct answer and to choose to explain the definition of the concept directly. It was also observed that some teachers made misleading or incomplete directions that were unrelated to the student error.

\section{Transformation Geometry}

The only test question in the category of transformation geometry is in the CK section. This question asks the respondents to determine if the five given definitions regarding the 
concepts of translation, expansion/scaling and congruency are right or wrong. 17 of the 23 teachers were unable to choose the correct definition of congruency, as follows: "Two shapes are congruent if they differ only in position and orientation in space." We observed that the respondents did not have an understanding of the condition of being congruent of two shapes. The incorrect response, selected by 10 participants, indicated a lack of understanding of the relationship between areas of similar shapes. Nearly half the teachers were unable to respond correctly as to whether an area of a shape will be doubled as a result of enlarging it with a scale factor of two. Another question related to how the edge lengths and therefore circumference of the shape will change when the shape is enlarged with a scale factor of one. Seven teachers were unable to explain the relationship of circumferences to the size of similar shapes. Likewise, seven teachers failed to define translation correctly.

\section{Discussion}

This section is organized according to the same structure used in the Findings section. We provide a discussion and interpretation of quadrilaterals, angle measurement and transformation geometry with the relevant conclusions from the related literature.

\section{Quadrilaterals}

Regarding quadrilaterals and their properties, it was clear that the participants did not know the basic features of a quadrilateral, for instance, a rhombus or a parallelogram. Although they understood the differences between types of quadrilaterals, they had difficulty in interpreting the similarities and differences. Participants often thought that any shape with two parallel edges was a parallelogram. We also observed that participants did not have an understanding of the concept of a parallelogram, utilizing incorrect definitions. In their study with prospective teachers, Wang and Kinzel (2014) worked with participants in terms of their geometric discourse and found that they had different discourses in defining some concepts such as parallelogram or rectangle. In another study, Marchis (2012) concluded that prospective teachers could not define fundamental geometric shapes because they lacked knowledge of the shapes' basic properties or characteristics. Being able to classify the quadrilaterals but not being able to perceive them in a hierarchical manner can be regarded as a deficiency in $\mathrm{CK}$, which has an effect on PCK as well.

The inadequacy in PCK regarding the rhombus question could be due to the deficiency in $\mathrm{CK}$, given that 14 participants did not recognize that a square is a rhombus. For this question, only one participant selected the correct answer regarding the appropriate feedback to the student. This suggests that there is an obvious relationship between the teachers' CK and PCK regarding quadrilaterals, which was consistent with the findings of Knievel et al. (2014). The researchers further concluded that the lack of CK and PCK in mathematics was the result of a deficient education of primary school teachers who were trained outside the specific field of mathematics teaching or a deficient teacher education period. Being out-of-field, they were not educated to teach mathematics specifically (Knievel et al., 2014).

The responses given to the question regarding the relationship between a square and a rectangle are also indicators of the important deficiencies of the participants in defining quadrilaterals. 13 of the 19 respondents who answered incorrectly claimed that a square was not a rectangle. We concluded that the participants understood quadrilaterals like squares and rectangles only superficially, in addition to being deficient in their ability to interpret their properties or describe the relationship between a square and a rectangle. Hourigan and Leavy (2017) stated that although the partici- pants knew basic theorems and axioms from their teacher education years, they lacked an understanding of the relationships and connections between them. This is due to extensive exam-oriented teaching with significant procedural experience at the university level (Hourigan \& Leavy, 2017). This conclusion leads us to another finding consistent with Jones (2002) that prospective primary school teachers perceive geometry as a straightforward subject compared to other learning areas.

Overall, primary school teachers' lack of CK and PCK seemed to be closely connected based on the findings of the study, even though their PCK was considerably less than their CK. Even though the participants in the study had a significant amount of teaching experience, an improvement in PCK depends on having a well-established understanding of geometry concepts and the relationships between them. Having enough CK in and of itself, however is insufficient to guarantee a well-established PCK (Jones, 2002). Studies conducted with prospective primary school teachers concluded that they demonstrated a lack of CK and PCK in nearly all the subjects for which they would be responsible (Turnuklu \& Yessildere, 2007). We assert that when teachers lack CK, they lack PCK as well, and that a well-developed PCK can be achieved through a well-achieved CK.

\section{Angle Measurement}

The responses to the angle measurement question related to similar triangles suggest that the majority of the teachers considered the nonlinear line segments as a linear line. This indicates a lack of CK about the concepts of linearity and angle. With only five out of 23 correct responses, we conclude that teachers' CK about angle measurement is incomplete.

Regarding PCK, it was observed that the teachers understood that the answer given by the student was incorrect, and for that reason they hesitated to provide the correct answer. However, many teachers tended to give a direct definition or clue that would lead the student to the answer directly. In addition, some teachers chose to give feedback which was unrelated to the correct answer provided by the student. This situation suggests that teachers had problems in determining which clues and guidance they would give to the student in the case of incorrectly answering a question. It was also concluded that the instructional explanations provided by the teachers to correct student errors were insufficient. The inadequacy of these instructional explanations is due to the lack of both CK and PCK in terms of angle measurement. A recent study shows that teachers have different interpretations about angles and how this mathematical concept was developed. That is, teachers cannot define or explain the angle as a concept (Silfverberg \& Joutsenlahti, 2014). Therefore, we conclude that what teachers understand about a mathematical concept affects their use of explanations, feedbacks and definitions which are all in the domain of their PCK. Another study reveals that prospective teachers had deficient geometry CK when they graduated from university and that their methodology courses for mathematics teaching were not sufficient to prepare them for lessons (van der Sandt \& Nieuwoudt, 2005). We claim that there are deficiencies in geometry CK of the primary school teachers included in our study and find that this conclusion is consistent with those in the related literature. In summarizing the deficiencies of both in-service or pre-service teachers, Jones and Tzekaki (2016) find that more research should be conducted so as to improve the geometry CK and PCK of teachers.

\section{Transformation Geometry}

The few existing studies of teachers' knowledge of transformation geometry suggest that teachers are not ready to teach transformation geometry concepts, as they had diffi- 
culties in understanding and explaining the concepts (Gomes, 2011; Köse \& Tanışll, 2014). Köse and Tanışlı (2014) found that pre-service primary school teachers could not explain how a shape dynamically changes after a transformation, such as rotational. This could be understood in the context of the changing nature of geometry teaching from the traditional Euclidean approach toward modern transformation geometry (Jones, 2002). Turkey also experienced this shift in geometry teaching that affected the elementary mathematics curriculum and appeared to be a sub-learning area called transformation geometry in both primary and elementary levels.

Jones and Fujita (2013) addressed congruency with a list of four different concepts, claiming that congruency should be considered a transformation concept. Based on our findings, the participants of the study seemed to lack this understanding of congruency since they could not describe whether shapes were congruent when their position or orientation in space changed. It could further be claimed that the participants were unable to analyze congruency in the case of a transformation, which is a concept that teachers are expected to grasp. Another study concluded that prospective teachers' understandings of translation in terms of motion concepts are weak because they lack the ability to define the translation while relating it with a plane, motion, transformation, or vector (Yanik, 2011).

\section{Conclusions and Implications}

Teachers' perceptions of geometry have a direct impact on their way of teaching and on the learning environments they offer to students, affecting their PCK (Aslan-Tutak \& Adams, 2015). More research is needed on how to develop improvements in perceptions of teachers and prospective teachers. Teacher education is crucial in this regard; geometry teaching should be carefully considered in the methodology courses offered in teacher education departments.

According to our study's findings, the elementary school teachers had deficiencies in the CK and PCK about basic geometry subjects such as quadrilaterals and their properties, angle measurement and transformation geometry. We determined that teachers were aware of these deficiencies and were willing to attend in-service training and courses in order to overcome their shortcomings. In this respect, we argue that courses and trainings related to geometry teaching should be offered not only to teacher candidates, but also to in-service teachers. A particular emphasis should be made on in-service training seminars for teaching geometry. Prospective teachers should also be supported with activities during their teacher education period (Cantürk-Günhan et al., 2009; Yanik, 2011; Ding et al., 2005). More research is needed with primary school teachers in order to analyze how to improve the knowledge they need to teach geometry and how their CK and PCK affects students geometric thinking.

\section{References}

Aslan-Tutak, F., \& Adams, T. L. (2015). A study of geometry content knowledge of elementary preservice teachers. International Electronic Journal of Elementary Education, 7(3), 301-318.

Ball, D. L., Thames, M. H., \& Phelps, G. (2008). Content knowledge for teaching: What makes it special? Journal of Teacher Education, 59(5), 389-407.

Ball, D. L., Hill, H. C., \& Bass, H. (2005). Knowing mathematics for teaching: Who knows mathematics well enough to teach third grade, and how can we decide? American Educator.

Browning, C., Edson, A. J., Kimani, P., \& Aslan-Tutak, F. (2014). Mathematical content knowledge for teaching elementary mathematics: A focus on geometry and measurement. The Mathematics Enthusiast, 11(2), 333-383.
Callingham, R., Beswick, K., Chick, H., Clark, J., Goos, M., Kissane, B., Serow, P., Thornton, S., \& Tobias, S. (2011). Beginning teachers' mathematical knowledge: What is needed? In J. Clark, B. Kissane, J. Mousley, T. Spencer and S. Thornton (Eds.) Mathematics: Traditions and [New] Practices (Proceedings of the 23rd AAMT Biennial Conference (AAMT) and the 34th Annual Conference of the Mathematics Education Research Group of Australasia (MERGA)), p. 828-835. Alice Springs: Australia.

Cantürk-Günhan, B., Turgut, M., \& Yılmaz, S. (2009). Spatial ability of a mathematics teacher: The case of Oya. IBSU Scientific Journal, 3(1), 151-158.

Chapman, O. (2015). Mathematics teachers' knowledge for teaching problem solving. LUMAT (2013-2015 Issues), 3(1), 19-36.

Charalambous, C. Y. (2016). Investigating the knowledge needed for teaching mathematics: An exploratory validation study focusing on teaching practices. Journal of Teacher Education, 67(3), 220-237.

Creswell, J. W. (2007). Qualitative inquiry and research design: Choosing among five approaches. 2nd Ed. Sage Publications.

Ding, L., Fujita, T., \& Jones, K. (2005). Developing geometrical reasoning in the classroom: learning from highly experienced teachers from China and Japan. In, Bosch, M. (ed.) European Research in Mathematics Education IV. Barcelona, Spain: ERME, pp. 727-737. ISBN: 8461132823

Hill, H. C., Ball, D. L., \& Schilling, S. G. (2008). Unpacking pedagogical content knowledge: Conceptualizing and measuring teachers' topic-specific knowledge of students. Journal for Research in Mathematics Education, 39(4), 372-400.

Hill, H. C., Schilling, S. G., \& Ball, D. L. (2004). Developing measures of teachers' mathematics knowledge for teaching. The Elementary School Journal, 105(1), 11-30.

Hourigan, M., \& Leavy, A. M. (2017). Preservice primary teachers' geometric thinking: Is pre-tertiary mathematics education building sufficiently strong foundations? The Teacher Educator, 52(4), 346-364.

Hoover, M., Mosvold, R., Ball, D. L., \& Lai, Y. (2016). Making progress on mathematical knowledge for teaching. The Mathematics Enthusiast, 13(1), 3-34.

Jones, K. (2002). Issues in the teaching and learning of geometry. In L. Haggarty (Ed), Aspects of Teaching Secondary Mathematics: Perspectives on Practice. London: Routledge Falmer. Chapter 8, pp 121-139. ISBN: 0-415-26641-6.

Jones, K. (1998). Theoretical frameworks for the learning of geometrical reasoning. Proceedings of the British Society for Research into Learning Mathematics, 18(1-2), 29-34.

Jones, K., Mooney, C., \& Harries, T. (2002), Trainee primary teachers' knowledge of geometry for teaching. Proceedings of the British Society for Research into Learning Mathematics, 22(2), 95-100.

Jones, K., \& Tzekaki, M. (2016). Research on the teaching and learning of geometry. In A. Gutiérrez, G. Leder \& P. Boero (Eds.), The Second Handbook of Research on the Psychology of Mathematics Education: The Journey Continues (pp. 109-149). Rotterdam: Sense. 
Kleickmann, T., Richter, D., Kunter, M., Elsner, J., Besser, M., Krauss, S., \& Baumert, J. (2013). Teachers' content knowledge and pedagogical content knowledge: The role of structural differences in teacher education. Journal of Teacher Education, 64(1), 90-106.

Knievel, I., Lindmeier, A. M., \& Heinze, A. (2015). Beyond knowledge: Measuring primary teachers' subject-specific competences in and for teaching mathematics with items based on video vignettes. International Journal of Science and Mathematics Education, 13(2), 309-329.

Köse, N., \& Tanışlı, D. (2014). Primary school teacher candidates' geometric habits of mind. Educational Sciences: Theory and Practice, 14(3), 1220-1230.

Krauss, S., Brunner, M., Kunter, M., Baumert, J., Blum, W., Neubrand, M., \& Jordan, A. (2008). Pedagogical content knowledge and content knowledge of secondary mathematics teachers. Journal of Educational Psychology, 100(3), 716.

Kumar, R. (2019). Research methodology: A step-by-step guide for beginners. Sage Publications Limited.

Marchis, I. (2012). Preservice primary school teachers' elementary geometry knowledge. Acta Didactica Napocensia, 5(2), 33-40.

Milli Eğitim Bakanlığı (MoNE), (2018). Matematik dersi öğretim programı (ilkokul ve ortaokul 1, 2, 3, 4, 5, 6, 7 ve 8. sınıflar) [School mathematics curriculum (primary and elementary level 1-8]. MEB Yayınları: Ankara.

Shulman, L. (1987). Knowledge and teaching: Foundations of the new reform. Harvard Educational Review, 57(1), $1-23$.

Silfverberg, H., \& Joutsenlahti, J. (2014). Prospective teachers' conceptions about a plane angle and the context dependency of the conceptions. In Proceedings of the 38th Conference of the International Group for the Psychology of Mathematics Education, Canada, (36)5, pp. 185-192.

Tsang, F. K. W., \& Rowland, T. (2005). The subject matter knowledge of Hong Kong primary school mathematics teachers. Paper presented at: European Conference on Educational Research; UCD, Dublin, Ireland.

Unal, H., Jakubowski, E., \& Corey, D. (2009). Differences in learning geometry among high and low spatial ability pre-service teachers. International Journal of Mathematical Education in Science and Technology, 40(8), 997-1012.

van der Sandt, S., \& Nieuwoudt, H. D. (2005). Geometry content knowledge: Is pre-service training making a difference?. African Journal of Research in Mathematics, Science and Technology Education, 9(2), 109-120.

Wang, S. \& Kinzel, M. (2014). How do they know it is a parallelogram? Analysing geometric discourse at van Hiele Level 3. Research in Mathematics Education, 16(3), 288-305.

Yanik, H. B. (2011). Prospective middle school mathematics teachers' preconceptions of geometric translations. Educational Studies in Mathematics, 78(2), 231-260.

Žilková, K., Guncaga, J., \& Kopácová, J. (2015). (Mis)conceptions about geometric shapes in pre-service primary teachers. Acta Didactica Napocensia, 8(1), 27-35.
Toluk Uçar, Z. (2013). Öğretmen adaylarının pedagojik içerik bilgisi: Öğretimsel açıklamalar [Preservice teachers' pedagogical content knowledge: Instructional explanations]. Turkish Journal of Computer and Mathematics Education (TURCOMAT), 2(2), 87-102. 